\title{
Economía sin plan, sin mercado y sin autocrítica
}

\author{
Francisco Javier Ibisate S. J.
}

Este artículo es una invitación a reflexionar nuestro futuro económico, desde un escenario al mismo tiempo mundial y nacional, persuadidos de que los problemas mundiales son problemas nacionales. Por ello, hacemos referencias breves al funcionamiento de la globalización, que parece andar cabizbaja, al mercado y al comercio mundial en que estamos inmersos, al Consenso de Washington y al Fondo Monetario Internacional, a lo que hacían nuestros economistas de los años 1960 y 1970, a los problemas que hoy presenta la economía de los noventa, sugiriendo algunas propuestas que no pretenden ser recetas económicas. El deseo es que nos dejemos guiar por la realidad, la racionalidad y la autocrítica.

\section{Situemos el problema}

Próximos a iniciar un proceso electoral se ha generado un ambiente poco propicio para una reflexión razonada. En el mes de junio surge en la escena pública un abanico de candidatos a la silla presidencial, cuyos programas de gobiemo nos son aún desconocidos. La aparición de estos candidatos, procedentes de divergentes espectros ideológicos, ha despertado reacciones agresivas fruto de filias y fobias políticas, que nos hacen retroceder a los años de 1980. Incluso las llamadas "adverten- cias" de algunos funcionarios públicos se traducen como "amenazas" solapadas a los electores nacionales. Sin conocer programas y planes de gobierno, vuelve a aparecer el fantasma del comunismo. Da la impresión de que seguimos leyendo el futuro económico como "la televisión en blanco y negro", sin otras alternativas posibles, es decir, desde "un pensamiento único". El peligro real no es lo que no existe, sino lo que sí existe y actúa sobre nosotros. Eso tiene un nombre, la globalización neoliberal con los diez mandamientos del Consen- 
so de Washington: una religión. Esto significa que debemos leer el presente y próximo futuro de nuestra economía nacional desde este escenario mundial. Nos preguntamos a veces si estamos preparados para entrar en el océano de la globalización, cuando desde hace más de dos décadas que pasa "como un huracán” por encima de América Latina.

Al terminar el siglo $\mathrm{XX}$, llegamos a la conclusión histórica de que ninguno de los grandes sistemas o modelos económicos ha dado una respuesta humana a los problemas políticos, económicos y sociales, e incluso todos han irrespetado los derechos de la naturaleza, el medio ambiente en que vivimos. Al cerrar el siglo $\mathrm{XX}$, en septiembre de 2000, se reúne en Nueva York la Cumbre del milenio de las Naciones Unidas. La Declaración del milenio nos deja una triste imagen, al finalizar el siglo. Una sola frase es suficiente para nuestro propósito: "La globalización es muy beneficiosa para algunos y es potencialmente beneficiosa para todos, pero solo si los estados trabajan conjuntamente para que estos beneficios lleguen a todos. En contraste, miles de millones quedarán abandonados a la pobreza y otros países emergentes están a la merced de súbitos cambios económicos".

Anthony Giddens dedica a los europeos La tercera vía: la renovación de la socialdemocracia. Por supuesto que cada gobierno europeo entalla en la globalización, a su modo, la socialdemocracia y donde el gobiemo no lo hace, lo hace la oposición. En el fondo, está creciendo la nostalgia del Estado social de bienestar: la libertad social y la igualdad real, junto con la recuperación de la solidaridad y la ciudadanía, frente al individualismo neoliberal. No debemos olvidar que ha sido en el continente latinoamericano donde ha surgido el movimiento cívico mundial de Porto Alegre como una inspiración para el nuevo milenio. El foro social mundial congregó a 20 mil participantes, en 2001; a 50 mil, en 2002 , y a $100 \mathrm{mil}$, en enero de 2003 , venidos de más de 150 países diferentes, con el lema: "Otro mundo mejor es posible". No es propiamente un movimiento antiglobalización, pero sí analiza sus ejes mayores para crear una globalización donde quepa toda la humanidad. El foro social busca dos grandes objetivos: presentar la globalización desde la visión de los sectores más inmersos en la sociedad civil y la participación activa de ésta en la formulación de un nuevo orden mundial. Se trata de completar una globalización "desde abajo".
Este artículo es una invitación a reflexionar nuestro futuro económico, desde un escenario al mismo tiempo mundial y nacional, persuadidos de que los problemas mundiales son problemas nacionales. Por ello, hacemos referencias breves al funcionamiento de la globalización, que parece andar cabizbaja, al mercado y al comercio mundial en que estamos inmersos, al Consenso de Washington y al Fondo Monetario Internacional, a lo que hacían nuestros economistas de los años 1960 y 1970, a los problemas que hoy presenta la economía de los noventa, sugiriendo algunas propuestas que no pretenden ser recetas económicas. El deseo es que nos dejemos guiar por la realidad, la racionalidad y la autocrítica.

\section{El contexto exterior}

\subsection{Desde el espejo retrovisor}

Cuando uno contempla el siglo $\mathrm{XX}$ desde el nuevo milenio llega a una conclusión: el mayor signo de debilidad y el peor enemigo que puede tener cualquier sistema económico es negarse a hacer su propia autocrítica. La autoadulación corrompe. La quiebra y la descomposición de los mal llamados "socialismos reales" del este europeo no ocumieron por la planificación de las economías, porque han existido variantes exitosas de planificación económica; lo que los perdió fue su permanente negativa a la autocrítica. Década tras década, grandes economistas e ingenieros (algunos de ellos Premios Nobel de Economía) propusieron profundas reformas del modelo económico y, década tras década, la nomenklatura se negó a escuchar y a aceptar estas propuestas. La Perestroika del equipo de $\mathbf{M}$. Gorbachov fue "el canto del cisne", antes de que se firmara, en Minsk, en 1991, la descomposición de la Unión Soviética.

El mismo defecto tiene la presente globalización neoliberal: se cierra a hacer su propia autocrítica, aunque grandes economistas, incluidos Premios Nobel de Economía, hablan sobre "el malestar en la globalización", el fracaso del "Consenso de Washington", sobre la necesidad de gobernar la globalización, porque la globalización hace difícil la globalización y porque "otro mundo es posible". Hay crítica, pero todavía no autocrítica, en bastantes cumbres mundiales, cuando la volatilidad de los capitales financieros especulativos desbarata economías y crea una crisis mundial, cuando de Seattle a Qatar se protesta por las asimetrías comerciales y se afirma 
que la teoría del libre comercio es "un fraude intelectual", cuando los manifestantes pacíficos gritan contra la "trinidad pagana" del Fondo Monetario Internacional, el Banco Mundial y la Organización Mundial del Comercio y se pide "otro Fondo", "otro Banco Mundial", cuando en la Cumbre del Milenio se dice "hay que reinventar Naciones Unidas", cuando en el foro económico de Davos de 1999 se dice que "la globalización es irresponsable" y ahí mismo, en 2003, los maestros del mundo afirman que su desafío es building trust, construir la confianza perdida.

En los intramuros de El Salvador, hemos heredado el mismo problema: el modelo se niega a hacer su propia autocrítica. En la década de los noventa, los tres gobiemos de turno han roto con una tradición del pasado: la era de los planes de desarrollo económico y social, con su correspondiente ministerio y la primera matriz insumo-producto, a modo de radar orientador de las políticas económicas. En esas décadas pasadas, éramos parte de ese ambiente de búsqueda mundial, inconformes, por razones históricas, con aquellos modelos dogmáticos, que se presentaban como el fin de la historia, y porque habían surgido, especialmente en Europa, otros modelos intermedios y alternativos. Se ha roto con esa tradición de búsqueda del modelo económico más idóneo para dar respuestas reales y duraderas, a nuestros desafíos económicos. Se impuso una lectura de la economía como la "televisión en blanco y negro", sin más altemativa, donde ni siquiera eran bien vistos quienes estaban en contra de uno y otro sistema.

La mala lectura que se hizo de la guerra civil, como un enfrentamiento de modelos antagónicos este-oeste, Unión Soviética-Estados Unidos, puso fin a la búsqueda de altemativas, con la imposición del "pensamiento único": Hacia una economía de mercado, FUSADES, 1989. El dogma no deja espacio a la discusión razonada, en el Foro de Concertación Económica y Social, y lo que es tan malo o peor, se cierra a reconocer las fallas y el fracaso del modelo. He aquí un testimonio de la Asociación Nacional de la Empresa Privada: "El actual modelo económico del país se fundamenta en los principios filosófico-doctrinarios de la economía de mercado. Las bases de este modelo fueron trazadas hace más de una década y con el tiempo han tendido a estructurarse a través de un proceso de desregulación, privatización y eliminación de controles de parte del Estado, apoyados en un proceso de apertura frente al exterior. Esto significa que el sistema económico funciona con un alto grado de libertad, en donde el mecanismo de los precios y la soberanía del consumidor promueven la competencia entre los distintos agentes económicos que participan en el mercado. Por definición, esto también significa la eliminación de la intervención arbitraria del Estado en las decisiones de inversión de los mismos agentes" (II ENADE, 2001, p. 10).

Éste es un típico caso de autoengaño. El mejor y más breve comentario de estos párrafos es una inocente pregunta: ¿cómo se han podido hacer estas afirmaciones en El Salvador del año 2001? ¿"Soberanía del consumidor", cuando el 50 por ciento de la población sobrevive entre la extrema y la relativa pobreza y cuando ha habido que esperar cinco años para que se hagan unos reducidos incrementos del salario mínimo y los campesinos deberán esperar otro lustro? ¿"Libre competencia" empresarial, cuando está en la sala de espera la "ley de libre competencia" y cuando el informe de II ENADE, cuatro páginas más adelante, reconoce que no somos "competentes"'? "El Salvador presenta serias limitaciones para enfrentar los retos de la globalización y la revolución mundial del conocimiento, ya que el desarrollo de la ciencia y tecnología en el país ha sido históricamente escaso y no se observan signos de mejora sustancial" (p. 14). Se engavetaron los análisis y las recomendaciones de la mesa de trabajo sobre "Ciencia y tecnología", Capítulo IV de los Temas claves para el plan de nación. ¿Cómo se puede afirmar "la eliminación de la intervención arbitraria del Estado", cuando aprobaron que el Estado, en forma poco transparente y muy festinada, "desnacionalizara" empresas y servicios públicos nacionales? Esto es lo paralizante del dogma económico, que se cierra a la autocrítica y no admite alternativas al modelo económico. Esto es autoengaño, porque la gente es buena, pero no es tonta.

En los años 1997-1999, varios grupos de profesionales y varios institutos de investigación presentaron una serie de programas y planes de nación que el gobierno ha relegado a los anaqueles de las bibliotecas. Lo que nos está perdiendo es esa ficticia seguridad (los BB+ imaginarios) y, por ello, nuestra economía es ahora más insegura que nunca. Hemos llegado a la parálisis de "una economía sin plan y sin mercado". Y lo peor de todo, sin autocrítica. Sufrimos el mismo mal que la globalización actual. La intención del presente comentario es mos- 
trar que tenemos que cambiar de rumbo, porque la globalización no funciona para beneficio de todos y porque sus ejes $y$ actores en poco o en nada han consolidado nuestras economías. Por ello, antes de hacer una propuesta sobre el cambio de rumbo, nos detenemos en una evaluación de algunos de los ejes y actores de esta globalización parcial y discriminante.

\subsection{Desde la cumbre de Davos}

Desde 1970, en el "foro económico mundial" de Davos se reúnen los "maestros del mundo". ¿Cómo ven ellos la economía mundial, la que ellos preconizan? Deducimos, según sus propias conclusiones, que la globalización está gravemente enferma, por sí misma y por las deseconomías externas que genera en la periferia circundante. Necesariamente, tenemos que presentar este diagnóstico en forma abreviada.

En el foro de Davos de 1999, luego de la crisis financiera mundial de 1997-1998, los documentos de antecedentes afirman que "la globalización es irresponsable", porque nadie responde y nadie se hace responsable de los efectos destructivos generados en la economía mundial, sobre todo en las débiles economías de los países pobres y emergentes. Soros dijo que "el mercado de los capitales financieros especulativos es inestable por naturaleza" (Entorno económico mundial, UCA Editores, 2003, pp. 138s.). En el foro económico de Davos de 2000 se hace el panegírico de la "nueva economía", de cuño norteamericano: el totem de Internet. Es la euforia del "nuevo comienzo", que dura menos de un año. En diciembre de 2000, Greenspan afirma: "nuestra tasa de crecimiento probablemente es cercana a cero" (ibídem, p. 156). La agenda del foro económico de Davos de 2001 tiene como objetivo "recuperar el crecimiento y corregir las desigualdades". La incógnita: ¿recesión mundial? La agenda del Foro Social Mundial de Porto Alegre anuncia: "otro mundo es posible" (ibídem, p. 196).

En Davos de 2002, en Nueva York (la ciudad mártir), una triste agenda: "economía frágil, inseguridad; la globalización de la ira se ha ido acelerando con el rápido crecimiento de las desigualdades". Un chivo expiatorio: "el eje del mal". Volvemos a la era de una "economía de guerra" mundial, con todas sus consecuencias. En el foro económico de Davos de 2003, la agenda toca fondo: "construir la confianza" (building trust). La economía mundial ha perdido lo último que podía perder: su confianza. El resultado de las encuestas, distribuidas en Davos, dice lo suficiente: "Los dirigentes de empresas están masivamente perdiendo la confianza del público". De todas las categorías, "los dirigentes de las organizaciones no gubernamentales son los más creíbles para la mayoría de ciudadanos $(56 \%)$, seguidos por los líderes de Naciones Unidas y jefes religiosos (41 y $42 \%$ )". "A los dirigentes de Estados Unidos se les concede la menor confianza". Y para que las cosas queden claras: "una mayoría de los ciudadanos está en desacuerdo con la dirección en que evoluciona el mundo" (Realidad, 2003, pp. 11-38).

La globalización está gravemente enferma en cuerpo y en espíritu. En cuerpo porque ha perdido su propia confianza, y en espíritu porque se ha deteriorado su conciencia. Las cumbres de la Organización Mundial del Comercio, desde Seattle hasta Qatar, y después de Qatar, también han sido decepcionantes. El comercio internacional, que debía ser un motor de crecimiento económico, no deja espacio para que jueguen las escasas ventajas competitivas del tercer mundo. Joseph Stiglitz ha dicho que la teoría del libre comercio es "un fraude intelectual", y su práctica, una hipocresía: no hacen lo que predican. Las cumbres del G-7, en Okinawa, Génova y Evian son igualmente decepcionantes y solo han servido para profundizar la desesperanza de quienes participan como "invitados de piedra". Los mismos foros económicos de Davos no son "mundiales", porque sus agendas no se mueven fuera de ciertos meridianos y paralelos, y terminan diciendo que han perdido su confianza.

Con el estallido del terrorismo, que para algunos gobiemos es un invento que nace el 11 de septiembre, éste se convierte en el problema "número uno" de la humanidad y en su nombre se legitiman guerras, atropellando las normas del derecho internacional y aduciendo pruebas que luego resultan ser falsas, un "título colorado" como la sangre. Pese a la amenaza mundial sobre el medio ambiente, hay gobiernos - grandes contaminadores - que se niegan a ratificar el Protocolo de Kyoto y casi los mismos gobiernos retiran su firma de los estatutos de la Corte Penal Internacional, ajenos a los crímenes de guerra, que ellos han podido provocar. Con toda razón se ha perdido la confianza en los ejes de esta globalización que, ciertamente, no es norma de moralidad. Hay que buscar en otro lugar los principios doctrinarios que inspiren nuestra convivencia social. 
Se ha asociado el "Consenso de Washington" al nombre de una persona, John Williamson, quien, en 1990 (luego de la caída del muro de Berlín), tradujo a recetas económicas el nuevo "pensamiento único", y que más recientemente ha reconocido el fracaso de su aspirina económica. De hecho y en verdad, el "Consenso de Washington" es Washington y asociados, para lo cual hubo que transfigurar, en el tiempo y el espacio, las funciones históricas que dieron nacimiento al Fondo Monetario Internacional y al Banco Mundial. La palabra consenso es una falacia, un gran engaño, porque desde una perspectiva etimológica daría a entender una concertación, un diálogo participado, cuando en realidad es una nueva forma de planificación de la economía mundial, en nombre de la "racionalidad económica". Y ¿qué ordena el Consenso de Washington?

\subsection{Las políticas del Consenso de Washington}

John Williamson nos hizo el favor de resumir los principales criterios o políticas del Consenso de Washington y sobre todo de decir que han fallado. ¿Cuáles son estas políticas? "La subordinación del papel del Estado al del mercado, la liberalización de los tipos de cambio, de intereses y de inversiones extranjeras directas, la disciplina fiscal, la máxima participación posible en los intercambios internacionales y la promoción del comercio exterior; la privatización de las empresas públicas, la consideración del progreso social no como una prioridad, sino como una consecuencia del crecimiento económico, la garantía absoluta de los derechos de propiedad privada y la afirmación de que solo existe un modelo racional de desarrollo". José Vidal Beneyto hace un buen resumen, en su artículo "El desarrollo como negocio", escrito con ocasión de la cumbre de Monteпеy, "El alivio de la pobreza", en marzo de 2002 (El País, 23 de marzo de 2002).

Los principios doctrinarios de la Asociación Nacional de la Empresa Privada (II Enade 2001) son muy afines al Consenso de Washington y, además, están referidos al documento de la directiva de FUSADES, Hacia una economía de mercado (1989), cuyos parámetros económicos son los si- guientes: la propiedad privada es condición necesaria para la eficiencia de la producción, el mercado libre asegura la mejor asignación de los recursos, la competencia garantiza el funcionamiento del mercado, y el Estado tiene un papel subsidiario. (Un comentario a estos principios puede leerse en Entorno económico mundial, pp. 99-107.)

Un término central que se maneja en todos estos documentos es el "mercado", que siendo algo tan importante, nunca se nos detalla qué es y cómo funciona. Es un concepto que se da por supuesto y que no asusta. Para la gente común y corriente mercado es la tienda o el supermercado cercano, donde hace las compras de cada día. Por simple sumatoria, mercado son todos los supermercados y las empresas nacionales que generan el producto nacional bruto. Para otros, mercado significa "el bloque empresarial hegemónico salvadoreño" ( $E C A$, 2002, pp. 605-695), análisis que sí nos acerca al concepto del "mercado regulador" del Consenso de Washington.

El mercado actual son, al menos, tres grandes mercados. El primero es el mercado de las empresas multinacionales. Sus directivos asisten cada año, desde 1970, al foro económico mundial de Davos, desde donde otean el horizonte económico, porque su cifra anual de negocios es 20 veces el producto interno bruto salvadoreño. Con su peso podrían derribar todas las fronteras, pero no es necesario, porque la teoría imperante ordena que los estados "deben facilitar los flujos de mercancías y capitales y fomentarlos con subvenciones inmensas y que en tamaño superan la cantidad de subvenciones que el Estado Social jamás haya efectuado" (F. Hinkelammert, ECA, 1997, p. 804). Sin embargo este voluminoso mercado es como una gran pantalla, que esconde sus duras consecuencias para nuestros mercados. Se trata de las "empresas de producción mundial" S. A., que vienen realizando, en forma simultánea o secuencial, tres grandes revoluciones tecnológicas. La gran revolución industrial, desde el siglo XIX, que J. Schumpeter definió como "un proceso de creación destructiva" (o destrucción creativa), que sentencia la desaparición de los métodos obsoletos de producción, en los países periféricos, además de 
oleadas de desempleo, en su propio país. En las dos o tres décadas finales del siglo XX, la revolución informática y el "tótem" de Internet, la "nueva economía", que requiere mano de obra o conocimientos más calificados, ha generado una amplia barrida de empleos, en el área administrativa de los servicios públicos, del sector privado, de todo el sistema bancario-financiero, aseguradoras y otros, como lo ha descrito Edward Luttwak, en su obra Turbocapitalismo. Por añadidura, los especializados programas informáticos son rápidamente asegurados por los "derechos de propiedad intelectual", derechos onerosos o imposibles para los países pobres. La informática ha generado una "brecha digital", que amplía la brecha económica entre quienes pueden y no pueden usarlos, incluso al interior de cada país.

En la última década del siglo $\mathrm{XX}$, otra revolución amenaza la supervivencia de muchas economías agrarias. $\mathrm{La}$ "revolución genética", llamada agrobusiness, se apropia de los secretos de la naturaleza, los modifica y los acelera para producir plantas y semillas que - sin probar si son buenas o malas para la salud y el medio ambiente - se convierten en una "creación destructiva" de la producción agraria, en el tercer mundo. Así, estas tres grandes revoluciones tecnológicas amenazan la sobrevivencia de los sectores primario, secundario y terciario del resto del mundo. Así es como juega y nos afecta este primer mercado del Consenso de Washington. No es de extrañar que, en la reunión de Quebec, en abril de 2001, numerosos manifestantes latinoamericanos se opusieron a la firma del ALCA, de la misma manera que en Porto Alegre se oponen a su ratificación. En su medida, esto vale para el tratado de libre comercio de El Salvador con Estados Unidos.

El segundo mercado es el de los capitales financieros, que circulan de bolsa en bolsa de valores. Su tamaño es exorbitante. En cuatro días de compra y venta de títulos y divisas se manipula más dinero que el generado por el producto interno bruto anual de Estados Unidos o que el producto mundial de un mes. En 1997-1998, estos capitales especulativos gestaron la crisis financiera mun- dial, desde el epicentro de los "tigres asiáticos" y desbarataron una serie de economías pobres y emergentes. Además, la especulación financiera y las quiebras fraudulentas sacudieron a la propia "nueva economía" de Estados Unidos, desde el año 2000, antes del 11 de septiembre. Desde 1998, grandes economistas (D. Rodrik, J. Stiglitz, P. Krugman, P. Samuelson y G. Soros) solicitaron controlar estos capitales, porque su libre circulación no beneficia el desarrollo de los pueblos.

Se ha dicho que este mercado ha hecho posible "un capitalismo popular", en el cual los hogares se sienten copropietarios de las grandes empresas. Lo que no se ha dicho es que esa copropiedad ha generado, en algunos países — sobre todo en Estados Unidos- la "propensión a especular", que, en el fondo, es el arte de vivir del trabajo ajeno. En el año 2000 , con la euforia de la "nueva economía", muchos hogares se endeudaron para adquirir títulos de empresas de telecomunicación, pues esperaban que sus cotizaciones seguirían subiendo. Larry Summers, Secretario del Tesoro, y Stanley Fischer, del Fondo Monetario Internacional, lo advirtieron a tiempo, en enero de 2000. Cuando el mercado dio vuelta, muchos hogares perdieron sus ahorros y descendió el "índice de confianza de los consumidores". Una vez más, igual que en 1930, la especulación volvió a sacudir a la economía más fuerte del mundo, en plena expansión. Ahora se trata de ejercer un estrecho control sobre estos mercados financieros porque, a través de estos canales, circulan las aguas negras del tráfico de la droga, de las armas, de la prostitución organizada, del tráfico de emigrantes y, por añadidura, de la "economía del terror", los fondos que sostienen toda suerte de terrorismos.

El tercer mercado es el de los medios de comunicación mundial. Son los grandes oligopolios o monopolios, que nos transmiten al instante no solo los hechos y sucesos, sino la retina o la lente con que debemos interpretarlos: "la guerra humanitaria" de Serbia-Kosovo, "la liberación de Irak", el "irresponsable Consejo de Seguridad" de Naciones Unidas. Este es el mercado que sirve para clonar el "nuevo homo oeconomicus", es decir, los gran- 
des principios del "pensamiento único". Para ello utiliza la poderosa influencia de instituciones financieras internacionales, como el Fondo Monterario Internacional y el Banco Mundial. En este marco o estructura del mercado mundial cabe un breve paréntesis sobre lo que podemos llamar el segundo mandamiento del Consenso de Washington que, en expresión de J. Stiglitz, es una de las causales de El malestar de la globalización. Lo hacemos por estar inmensos en las negociaciones del tratado de libre comercio con Estados Unidos.

\subsection{La promoción del comercio exterior}

Uno de los ejes centrales del Consenso de Washington es "la máxima participación posible en los intercambios intemacionales y la promoción del comercio exterior”. ¿Por qué el libre comercio, algo tan necesario para el desarrollo de las naciones, se ha convertido en el centro del debate y del rechazo mundial? La respuesta es sencilla: porque "el libre comercio no es un comercio libre". No es la primera vez en la historia en que el comercio ha sido utilizado como instrumento de colonización abierta o disfrazada. La confrontación aparece ya entre las grandes potencias y los mercados comunes. Al terminar la guerra fría, el historiador Lester Thurow publicó Head to head. Con permiso del autor, la traducción española la titula La guerra del siglo XXI: la batalla económica que se avecina entre Japón, Europa y los Estados Unidos (Barcelona, 1992). Este título recuerda la película El parque de los dinosaurios.

El problema y el debate mayor se presentan en los intercambios entre pequeñas y grandes naciones. La desregulación, la liberalización, la privatización y la promoción del comercio exterior son la cuadriga neoliberal del colonialismo económico. Un ejemplo y una amenaza siempre pendiente es la reunión del ALCA, en Quebec, en abril de 2001. No se puede negar que algunos discursos rezuman una ideología poco o nada confirmada por la historia. G. W. Bush dijo: "Creo que el comercio es importante para este hemisferio. No solo expande la prosperidad, sino que ayuda a expandir la libertad; un hemisferio democrático, ligado por la buena voluntad y el libre comercio". Algunos de los mandatarios firmantes coreaban al anfitrión: "El libre comercio sin subsidios, ni prácticas desleales, acompañadas de flujos crecientes de inversión productiva y de una mayor integración económica, favorecen la prosperidad regional, mejorando las con-

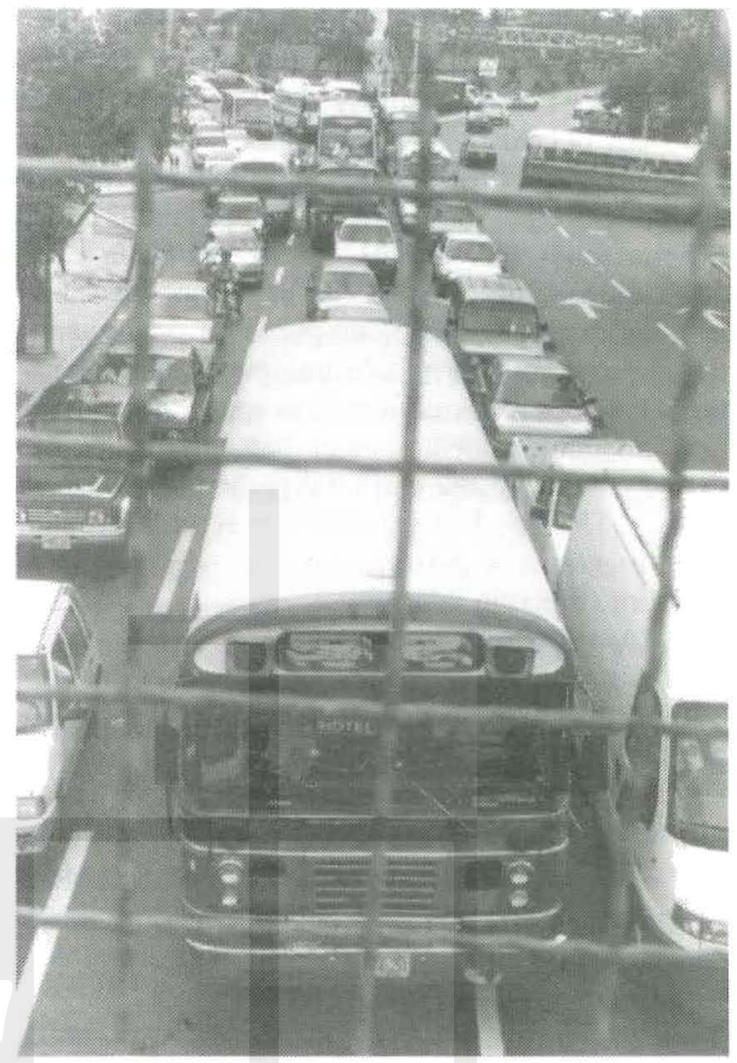

diciones laborales de los pueblos de las Américas y protegen mejor el medio ambiente". No hay duda de que éste es un "bello canto" a la utopía, es decir, una buena crítica a la realidad.

No fue éste el parecer de Fernando Cardoso quien, además de presidente de Brasil, es un buen economista. En su discurso criticó las medidas antidumping de Estados Unidos y las asimetrías existentes, en bienes agrícolas. "El ALCA será bienvenido si su creación significa un proceso para dar acceso a los mercados más dinámicos, si efectivamente significa el camino para las reglas compartidas antidumping, si reduce las barreras arancelarias, si evita la distorsión proteccionista de las buenas reglas sanitarias. Pero si no es así, sería irrelevante o, en el peor de los casos, indeseable" ( $E l$ ALCA, un acuerdo entre desacuerdos", ECA, 2001, pp. 713-714; "El ALCA, libre comercio con plan de nación", Realidad, 2001, p. 252).

Estos debates son relevantes, porque EI Salvador está embarcado en un tratado de libre comercio con Estados Unidos, para el cual este tratado, 
de acuerdo con la bibliografía citada, es, ante todo, una conquista política, un pasadizo hacia la integración del Pacto Andino y del MERCOSUR, en la órbita del ALCA -800 millones de personas agrupadas, en el mayor mercado mundial, frente a la zona euro. De momento, el 62 por ciento de las exportaciones salvadoreñas se dirigen hacia Estados Unidos y de allí procede el 50 por ciento de las importaciones. Desde un punto de vista cuantitativo no es mucho más lo que pueden incrementarse las relaciones comerciales entre ambas partes, tomando en cuenta que el mercado centroamericano es una ínfima parte del comercio global de Estados Unidos. Las razones son otras. Leyendo, simplemente, la historia del libre comercio intemacional, en los tres últimos años, hay derecho a "tener miedo" a un tratado de libre comercio con Estados Unidos, porque suele practicar "la guerra preventiva comercial".

Cuando se firmaba el pacto de Quebec, en 2001, J. Stiligtz compaginaba su obra El malestar en la globalización, donde deja escurrir muchas veces el término "hipocresía", una fuerte acusación. "Los críticos de la globalización acusan a los países occidentales de hipocresía, con razón; forzaron a los países pobres a eliminar las barreras comerciales, pero ellos mantuvieron las suyas e impidieron a los países subdesarrollados exportar productos agrícolas, privándolos de una angustiosamente necesaria renta vía exportaciones... Incluso cuando occidente no fue hipócrita, marcó la agenda de la globalización y se aseguró de acaparar una cuota desproporcionada de los beneficios a expensas del mundo subdesarrollado... no fue solo que los países industrializados continuaron subsidiando la agricultura y dificultando la competencia de los países pobres, aunque insistieron en que éstos suprimieran los subsidios a sus bienes industriales. Los 'términos de intercambio' - los precios que los países desartollados y menos desarrollados consiguen por las cosas que producen- después del último acuerdo comercial de 1995 (el octavo) revelan que el efecto 'neto' fue reducir los precios de algunos de los países más pobres del mundo en relación con los que pagan por sus importaciones. El resultado fue que algu- nas de las naciones más pobres de la Tierra empeoraron aún más su situación" (p. 34).

El mismo J. Stiglitz se dirigió a los miembros del G-7, reunidos en Génova, en julio de 2001. "El sistema del comercio intemacional está con problemas. Se predica el libre comercio como el evangelio en todas partes, pero parece que los países no hacen caso de su propio mensaje; sus mercados permanecen cerrados a muchos de los productos de los países en desarrollo, subsidian a sus agricultores en forma masiva, lo que hace imposible que los países en desarrollo puedan competir. El mensaje del G-7 parece ser: hagan lo que decimos, no lo que hacemos" (Entorno económico mundial, pp. 207-208). Un año más tarde, el Premio Nobel protesta por las masivas subvenciones agrícolas (22 mil millones de dólares, en 2002) a los granjeros: "Es la perfecta hipocresía de la administración Bush sobre la liberalización del comercio".

Si del nivel del gobierno pasamos al nivel de las empresas, descubrimos nuevos ardides de al-

gunas multinacionales para subvencionar sus exportaciones. Luego de cinco años de disputas y a solicitud de la Unión Europea, "la OMC impone sanciones a los Estados Unidos por $\$ 4.000$ millones". La Organización Mundial del Comercio declaró ilegal el sistema conocido como "Corporaciones de Ventas al Exterior", que permite a grandes empresas aplicar subsidios a la exportación, mediante la utilización de paraísos fiscales, desde los cuales realizan negocios con el exterior, reduciendo hasta 30 por ciento la carga impositiva. Así, han estado exportando empresas aeronáuticas y otras de servicios industriales como Kodak, Microsoft, General Motors, Caterpillar, Chrysler, Boeing... Una gran parte de cereales y de soya salen por este canal" (ibídem, pp. 214-218 y 239).

Un último testimonio del nuevo presidente de Brasil, Lula da Silva, en su discurso en el foro de Davos, en enero de 2003: "si ustedes quieren ser coherentes, ustedes no pueden y no deben plantar barreras a los países en desarrollo. Queremos un libre comercio que se caracterice por la reciprocidad. De nada valdrá el esfuerzo exportador que 
hagamos si los países ricos siguen predicando el libre comercio y practican el proteccionismo. $\mathrm{Si}$ los países ricos son negociadores duros, tampoco podremos hacer concesiones. No tiene sentido invertir si cuando vas a exportar te enfrentas con enormes barreras. No queremos ser tratados como ciudadanos de segundo orden, sino como iguales. Es urgente construir un nuevo orden económico con más justicia, un nuevo programa para un desarrollo mundial compartido, una nueva ética. Aquí en Davos no hay ahora más que un Dios, el mercado libre, pero el mercado libre debe tener como corolario la libertad y la seguridad de la población" (Realidad, 2003, p. 24).

Este mosaico de testimonios, que llegan desde el norte y desde el sur, prueba que el principio del bien se ha convertido en principio del mal. Quienes más necesitan el comercio internacional para asentar su desarrollo son los países del tercer mundo; pero los países industrializados han convertido la necesidad en asimetría, en hipocresía y en la principal causal de la deuda externa. No hay que rasgar todos los tratados comerciales, porque el comercio, realmente libre y entre similares, sirve para acuciar la capacidad competitiva. Se ha olvidado que desde 1960, el comercio internacional se realiza, más bien, entre mercados comunes que entre naciones y no hemos aprendido esta lección. Por una serie de hechos desafortunados, por ejemplo, seguimos siendo estados "desunidos" de Centroamérica, habiendo perdido así la gran oportunidad de integrar y fortalecer nuestras cercanas economías, antes de entrar al mar abierto. El mercado común europeo se constituyó entre seis naciones, que se habían enfrentado y destruido, en la más cruda segunda guerra mundial. Ahora, desde fuera, quieren forzar una unión del istmo para hacer una economía a su imagen y semejanza. Esto no va a funcionar por varias razones.

En políticas comerciales se han dado bandazos de babor a estribor: del prolongado e infructuoso proteccionismo, de las décadas pasadas, a una brusca disminución de las defensas arancelarias, en la actual. El recordado Salvador Osvaldo Bran decía de la primera época que un "Aspecto de singular importancia es cómo superar el patrón de comportamiento tradicional del sector empresarial que cree en el principio del menor esfuerzo tecnológico. El proteccionismo excesivo de varios decenios provocó que éste eludiera correr riesgos, en particular, los asociados a la innovación tecnológica. Muchos empresarios se han acostumbrado a no competir con mejor calidad y precio; prefieren hacerlo con publicidad, acceso a crédito preferencial y la obtención de subsidios del gobiemo, o sea, se habituaron a formas de competencia que exigen poco o ningún esfuerzo tecnológico, práctica que debe erradicarse para ser más competitivo" (ECA, 1997, p. 546).

Tampoco se aprendió la lección de los "tigres asiáticos" que, gracias a un pacto o entrelazamiento del Estado y del sector empresarial ("economía mixta"), tasas arancelarias de protección, limitaciones cuantitativas de importaciones, disciplina laboral, junto con sistemas públicos de educación y salud, lograron el fortalecimiento interno de su producción, antes de salir al océano del mercado mundial. Fundamentaron su desarrollo, no gracias a los principios de la teoría neoliberal, como hemos oído decir muchas veces. Sin estar tecnológicamente preparados, en virtud de una teoría demasiado dogmática, los gobiernos actuales han querido dar un salto en el vacío, con graves consecuencias para la economía, tal como los recuerda una autoridad nacional. Pero queda una pregunta: ¿quién inspiró y empujó al equipo económico de nuestros gobiernos a dar este salto en el vacío?

\section{5. “La década perdida": 1990}

El Dr. Álvaro Magaña, ex presidente y experto en ciencia fiscal, decía que "la política económica de la década de los noventa: necesidad de su revisión". Estas líneas guardan el sabor de un borrador, al mismo tiempo que tocan varios errores de los gobiernos actuales.

Así comenzó lo que nosotros llamamos la década perdida del neoliberalismo, cuando se inician las políticas que para la globalización exigían el FMI-BM, el binomio cuyo daño que nos ha hecho, tuvo un alto precio para la generalidad y que los obedientes líderes de la derecha, ya en el poder, aceptaron y hasta ayudaron para lograr la aprobación de políticas que ya es hora de revisar, pues estamos bastante retrasados en evaluarlas seriamente y modificarlas para bien del país.

Comenzaron bajando los impuestos de importaciones para abrir nuestros mercados a las importaciones, y reduciendo la tasa marginal más alta del impuesto sobre la renta a $25 \%$, o sea, un poco más de un tercio de lo que era en tiem- 
po en que había quienes entendían la ciencia de la hacienda, es decir, sabían lo que hacían, y cuando además actuaban con independencia y no siguiendo consignas de sectores económicamente poderosos. De igual modo, se suprime el impuesto sobre el patrimonio, el de sucesiones y el impuesto de donaciones, y se descansa exclusivamente en un tributo sobre el consumo, que en versión moderna, se llama impuesto al valor agregado, IVA, que encarece los consumos de muchos productos necesarios, y es básicamente regresivo, como lo dijimos en nuestro trabajo ("El Estado como sujeto de obligaciones tributarias", Estudio $N^{\circ} 14$ de la Corte Suprema de Justicia).

Cuando la "genialidad" del Ministerio de Economía de la época en que se bajaron los impuestos de importación, a principios de los noventa, unido a la falta de una política monetaria de verdad, no le permitió percibir que las pequeñas y medianas empresas serían diezmadas por su incapacidad para competir con los productos importados más baratos. Este borrador (de 29 páginas) fue redactado el 24 de abril de 2001, poco antes de que su salud se viera seriamente afectada. Es un borrador de quien sabe de qué habla y que no duda en hablar de "la década perdida del neoliberalismo".

El Dr. Magaña toca, en estas líneas, varios puntos que deben ser evaluados y modificados "para bien del país". Un punto inicial son "las políticas que para la globalización exigían el Fondo Monetario Internacional y el Banco Mundial, "el binomio" que tanto daño ha hecho. Una vez más recumimos al juicio calificado de J. Stiglitz, quien afirma que, en el siglo XX, hubo dos Fondos Monetarios y dos Bancos Mundiales. Los primeros fueron creados en Bretton Woods, en 1944, con el nombre de Fondo Monetario Internacional y Banco Intemaciona! de Reconstrucción y Fomento. Uno de los inspiradores fue Keynes, aunque prevaleció la propuesta de Harry D. White, por ser el dólar la única moneda respaldada por el oro, lo cual favoreció el predominio de Estados Unidos. ¿Por qué y para qué nacieron estas dos instituciones? En su concepción original, el Fondo Monetario Internacional reconoció que los mercados no funcionaban, lo cual podía dar lugar a un paro masivo y podrían fallar a la hora de aportar los fondos imprescindibles para que los países pudieran recomponer sus economías. El Fondo surgió de la creencia en la necesidad de una acción colectiva global para lograr la estabilidad económica. Ambas instituciones nacieron en un entomo de crisis de la economía de mercado. En 1930 ocurrió la décima tercera crisis de dicho modelo económico. Con esta inspiración y creencia se reconstruyeron las economías de los primeros destinatarios de ambas instituciones, que pasaron a ser los "socios y accionistas" de las dos ellas.

El Fondo Monetario Internacional ha cambiado mucho a lo largo del tiempo. Fundado en la creencia de que los mercados muchas veces funcionan mal, ahora proclama su supremacía con fervor ideológico. Fundado en la creencia de que es necesaria una presión internacional para que los países adopten políticas económicas expansivas -como elevar el gasto, bajar los impuestos o reducir los tipos de interés para estimular la economía-, en la actualidad, el Fondo da dinero solo si los países emprenden políticas como recortar los déficit, aumentar los impuestos y los tipos de interés, lo cual contrae la economía. Keynes se revolvería en su tumba si supiese lo que ha sucedido con su criatura... La orientación keynesiana del Fondo, que subrayaba los fallos del mercado y el papel del Estado en la creación de empleo, fue reemplazada por la sacralización de libre mercado, en los ochenta (R. Reagan y M. Thatcher), como parte del nuevo "Consenso de Washington" - entre el Fondo Monetario Internacional, el Banco Mundial y el Tesoro de Estados Unidos sobre las "políticas correctas" para los países subdesarrollados-, la cual marcó un cambio muy diferente en el desarrollo económico y la estabilización. Propició la liberalización de los mercados de capitales, a pesar de que no existen pruebas de que ello estimule el crecimiento económico.

J. Stiglitz recuerda que "la mayoría de países industrializados, incluidos Estados Unidos y Japón, 
edificaron sus economías mediante la protección sabia y selectiva de algunas de sus industrias, hasta que fueron lo suficientemente fuertes para competir con compañías extranjeras". Y a continuación, comenta el doble error cometido en distintas décadas: "Es verdad que el proteccionismo generalizado a menudo no ha funcionado en los países que lo han aplicado, pero tampoco lo ha hecho una rápida liberalización comercial. Forzar a un país en desarrollo a abrirse a los productos importados que compiten con los elaborados por algunas de sus industrias, peligrosamente vulnerables a la competencia de buena parte de industrias más vigorosas en otros países, puede tener consecuencias desastrosas, sociales y económicas. Se han destruido empleos sistemáticamente - los agricultores pobres de los países subdesarrollados no podían competir con los bienes altamente subsidiados de Europa y Estados Unidos - antes de que los sectores industriales y agrícolas de los países pudieran fortalecerse y crear nuevos puestos de trabajo".

A estos errores históricos se suma la irritabilidad mundial por los canales que utilizan estas instituciones internacionales para imponer su nuevo credo. Los problemas también se derivan de quién habla en nombre del país. En el Fondo Monetario Internacional son los ministros de hacienda y los gobernadores de los bancos centrales. En la Organización Mundial del Comercio son los ministros de comercio. Cada uno de ellos se alinea con grupos particulares, "en" sus propios países. Los ministros de comercio reflejan las inquietudes de la comunidad empresarial, tanto los exportadores, que desean nuevos mercados abiertos para sus productos, como los productores de bienes, que compiten con las importaciones. Estos grupos, por supuesto, aspiran a mantener todas las barreras comerciales que puedan y conservan todos los subsidios, obtenidos persuadiendo a sus asambleas o parlamentos. El hecho de que las barreras comerciales eleven los precios pagados por los consumidores o que los subsidios impongan cargas a los contribuyentes es menos importante que los beneficios de los productores. Las cuestiones ecológicas o laborales son aún menos importantes, salvo como obstáculos que han de ser superados. Estas personas ven naturalmente el mundo a través de los ojos de la comunidad financiera. Las decisiones de cualquier institución reflejan las perspectivas y los intereses de quienes las toman; no sorprende, pues, que las políticas económicas de las instituciones internacionales se ajusten en función de intereses comerciales y financieros de los países industrialmente avanzados.

Quienes a partir de 1945 se desarrollaron gracias al Fondo Monetario Internacional y al Banco Mundial y a políticas de cuño keynesiano, con positiva participación estatal, en la aplicación de políticas económicas (utilizando el radar orientador de las matrices intersectoriales de W. Leontief), ahora niegan estas vías de desarrollo a los países que más las necesitan. Este es el engaño mundial del Consenso de Washington, que no es un invento de John Williamson. No es de extrañar que en la cumbre de primavera del Fondo y del Banco, en Washington, en abril de 2000 , los manifestantes pacíficos protestaran contra "la trinidad pagana" del Fondo, el Banco y la Organización Mundial del Comercio, y pidieran "otro Fondo y otro Banco". Conviene recordar que $J$. Wolfensohn, director de segundo, en su discurso de octubre 1998, "La otra crisis", diera un paso importante, en la línea de autocrítica. Una línea similar encontramos en la cumbre del Fondo y del Banco, en Praga, en septiembre de 2000, donde participó Horst Kholer, presidente del primero y se habló de "un giro copernicano". Al menos verbalmente, reconocieron sus errores.

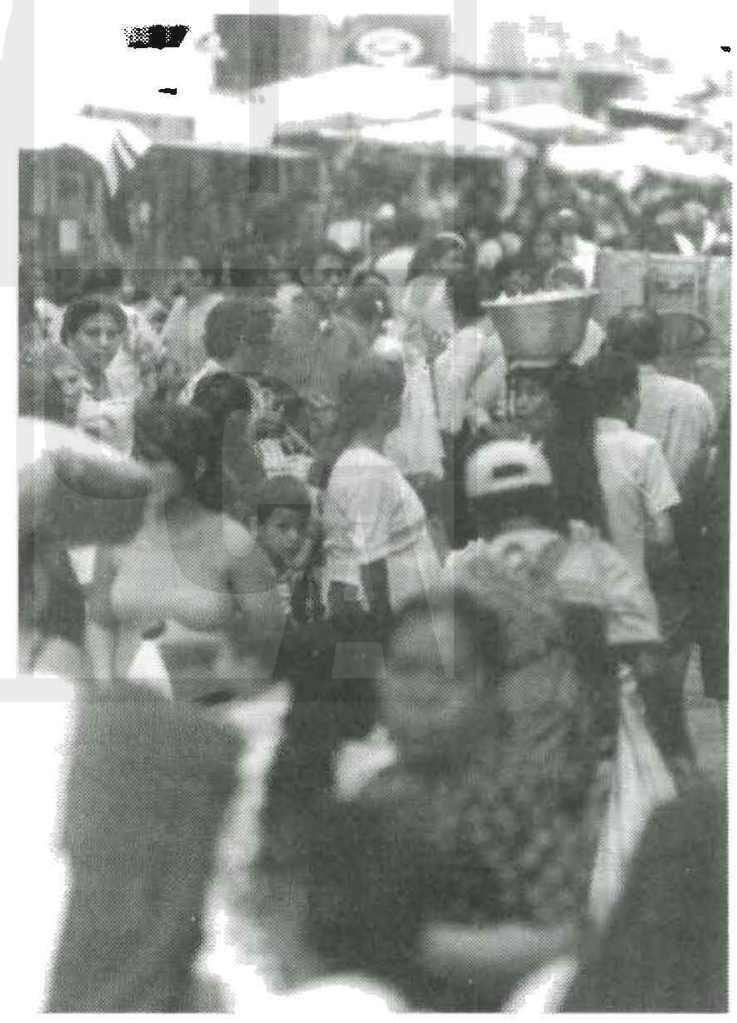


J. Stiglitz hace referencia a un fenómeno creciente, que derivará en el foro social de Porto Alegre, fenómeno que no parece haber sido percibido por nuestros gobiemos. "Sin altemativas, sin vías para expresar su inquietud, para instar a un cambio, la gente se alborota. Es evidente que las calles no son el sitio para discutir cuestiones, formular políticas o anular compromisos. Pero las protestas han hecho que funcionarios y economistas en todo el mundo reflexionen sobre las altemativas a las políticas del Consenso de Washington, en tanto que única y verdadera vía para el crecimiento y el desarrollo. Queda crecientemente claro no solo para los ciudadanos corrientes, sino también para los que elaboran políticas, y no solo en los países en desarrollo, sino también en los desarrollados, que la globalización, tal como ha sido puesta en prácti$\mathrm{ca}$, no ha conseguido lo que sus partidarios prometieron que lograría... ni lo que puede, ni debe lograr. En algunos casos, ni siquiera ha logrado crecimiento, y cuando lo ha hecho, no ha proporcionado beneficios a todos; el efecto neto de las políticas estipuladas por el Consenso de Washington ha sido favorecer a las minorías a expensas de la mayoría, a los ricos a expensas de los pobres. En muchos casos, los valores e intereses comerciales han prevalecido sobre las preocupaciones del medio ambiente, la democracia, los derechos humanos y la justicia social" (El malestar en la globalización, pp. 27-48).

Como recomendara el Dr. Magaña, ya es hora de revisar estas políticas impuestas en la pasada década, para evaluarlas con seriedad y modificarlas para bien del país. Varias instituciones ya lo hacen, incluso con asesoría de economistas extranjeros calificados, es de esperar que sea para bien del país. Este trabajo trata de iluminar nuestros problemas, desde el escenario mundial de los grandes mercados, del comercio internacional, de las instituciones financieras internacionales, en el supuesto de que esos son los ejes que han inspirado las políticas del gobiemo. Desde ese escenario, ahora descendemos para evaluar nuestra economía, en dos etapas.

\section{Evaluación de la economía salvadoreña}

\section{1. ¿Nos equivocamos en 1960-1970?}

Dado que la autocrítica puede ayudar a enderezar un modelo económico, debemos preguntarnos si estaban equivocados aquellos economistas que elaboraron los planes de desarrollo económico y social de 1968-1972 y 1973-1977 y aquellos técnicos nacionales y extranjeros del Banco Central de Reserva, que elaboraron las matrices insumo-producto de 1978 y 1990 . Todo eso se ha enterrado sin discutir si era bueno o era malo; se dio por supuesto que era innecesario. Sin embargo, queda en el aire la pregunta, ¿aquellos economistas estaban equivocados o tal vez hay que volver a "lo innecesario"?

Ahora los economistas tienen que seguir la economía de otra manera. En estos tiempos, la economía va por delante, en el supuesto de que algo o alguien la impulsa y la guía. Cada trimestre unos y cada semestre otros, presentan análisis de la coyuntura económica pasada, aunque "unos y otros" no leen de la misma manera a dónde nos lleva esta coyuntura. Este es el problema, porque "coyuntura" no es el estado presente de la economía; etimológicamente, es un futuro latino (cum-iunctura), ¿cuál será el resultado final de la cadena de coyunturas presentes? Es totalmente necesario seguir haciendo estos análisis de coyuntura, que miden el pulso de nuestra economía, que de 1996 a nuestros días da señales claras de desaceleración, estancamiento y desasosiego social. El déficit comercial y fiscal van a más y los índices de desarrollo humano a menos; pero valen más las condecoraciones $(\mathrm{BB}+)$, que nos obsequian algunos extraterrestres.

Se podrá decir que aquellos economistas de 1960-1970 no crearon nada nuevo, que simplemente copiaban lo que veían que se hacía, sobre todo, en bastantes países de Europa occidental, sacudidos por la crisis del mercado, en 1930, y golpeados, en cuerpo y alma, por la segunda guerra mundial. Tenemos ahora que reconocer que esos países, los primeros destinatarios y beneficiarios del Fondo Monetario Internacional y del Banco Mundial, gracias a la secuencia de "planes concertados", de economías mixtas y participativas, partiendo del desarrollo de su contabilidad nacional y del instrumento guía de las matrices insumo-producto, que enseñaban en sus universidades, dieron su gran salto cuantitativo y cualitativo. El plan Marshall puso la gasolina, pero esos países inventaron el motor. El Premio Nobel de Economía W. Leontief comentaba que sus matrices input-output se estaban utilizando, simultáneamente, en su tierra natal, Rusia, para una planeación centralizada, en Europa occidental, para una planeación concertada, y en Estados Unidos, donde las utilizaba sobre todo la gran empresa, para situarse en los sectores claves de la economía. Entonces, K. Galbraith dijo que la eco- 
nomía norteamericana está planificada por la gran empresa.

Hemos perdido algo muy importante al embodegar, en el Banco Central de Reserva, nuestras matrices insumo-producto, porque en su sencilla complejidad, recuerdan dos lecciones fundamentales de buena economía. Primero, que la economía tiene un orden a seguir, se le llame sector primario, secundario o terciario, o mejor, que existe una cadena productiva, donde cada sector es un eslabón. Segundo, que en la economía no hay "sectores", en el sentido de "sectas" separadas (ese ha sido uno de nuestros errores), sino ramas productivas, interrelacionadas e interdependientes. Los análisis comparativos de nuestras matrices de 1978 y 1990 mostraban - entre otras muchas cosas- cuáles eran sectores con mayor capacidad para dinamizar toda la economía, si hacia ellos se encauzara el crédito bancario. Nuestra estructura económica era todavía débil; nuestros productos primarios salían al exterior sin ninguna transformación interna, e importábamos la mayoría de bienes finales. La columna vertebral de la economía era débil $y$, de acuerdo a Hirschman, Chenery y otros investigadores, la podíamos consolidar con políticas de desarrollo "río-arriba y río-abajo". Para fortalecer los agregados macroeconómicos, había que integrar primero la estructura productiva interna.

La preocupación principal era fortalecer la estructura productiva interna. Luego, nos enteramos de que eso era lo que estaban haciendo los "tigres y dragones" del continente sudasiático, antes de salir a mar abierto. Las matrices insumo-producto eran un croquis de nuestra geografía económica: sus filas superiores mostraban que el sector primario agrícola estaba totalmente vertido al exterior, con muchas casillas "fantasmas", es decir, con escasas interconexiones con los sectores secundario y terciario, que se arremolinaban en las zonas urbanas. En realidad había dos El Salvador. Por lo tanto, era necesario crear polos de desarrollo internos, en el sector rural. W. Leonfief aconsejaba crear "familias o cadenas de industrias", in situ, donde escaseaba el empleo, a fin de lograr un "desarrollo equilibrado de las regiones". En esos años, los alumnos de introducción a la economía lamentaban el serio proceso de terciarización económica; decían que algo se debía hacer.

A aquellos economistas les preocupaba la estructura tecnológica o la estructura de costos de producción, porque las matrices de coeficientes téc- nicos de producción mostraban que éramos más dependientes de la repetitiva tradición que de los nuevos avances tecnológicos. Nos repetían la frase de W. Leontief: "los países pobres, a veces son pobres, no por carencia de recursos, sino porque no saben cómo emplearlos". Convenía leer y analizar las matrices de coeficientes técnicos de países algo más avanzados para ir integrando nuevos avances tecnológicos. Algunos economistas más atrevidos decían que si el Ministerio de Planificación utilizaba la séptima sábana de los coeficientes inversos de producción, se podía elaborar, con cercana aproximación, un plan de "desarrollo armónico" para el próximo quinquenio.

También se hicieron pequeños, pero importantes inventos: "Necesidades básicas y reactivación de la economía". Si, gracias a proyectos o trabajos públicos del Estado, que generasen empleo, en grupos de personas desempleadas, la sumatoria de estos ingresos, traducidos en demanda de la canasta básica, tendría - de acuerdo a la matriz y a su elevada propensión a consumir- un efecto multiplicador de 2725 , lo cual significaba que en la canasta básica popular se escondía un elevado poder dinamizador de la economía. Lo bueno de aquellos economistas es que se preocupaban por el desarrollo intemo nacional antes de salir a mar abierto, aunque todavía no se cantaba el himno de "primero El Salvador, segundo El Salvador, tercero El Salvador".

Nostalgias de un pasado promisorio y difícil. Promisorio, porque aquellos economistas buscaban un desarrollo económico y social integrado con la creación del mercado común centroamericano. Difícil, porque los poderes económicos miraban con sospecha eso de "planificación" de la economía y sobre todo algunas de las reformas recomendadas. Baste recordar la forma desairada con que terminó la convocatoria que hiciera la Asamblea Legislativa a un seminario sobre reforma agraria, a inicios de 1970, y la marcha atrás que el gobierno diera, en octubre de 1976, al proyecto de transformación agraria, oficialmente aprobado, en junio del mismo año. No hace falta repetir lo que sucedió. Se sustituyeron estos programas de bienestar social por el programa de "seguridad nacional" que, aunque suena parecido, es del todo diferente.

Mantenemos, sin embargo, la nostalgia, porque la secuencia de análisis de coyuntura y los informes anuales de desarrollo humano nos muestran que es cierto lo que dijera el presidente, el 22 de 
noviembre de 2000 , al presentar la dolarización: "Todos en el país sabemos que nuestra economía, después de lograr éxitos muy marcados, está experimentando un 'entrampamiento', que ha generado un negativismo muy nocivo para el desarrollo del país". Lo que no se nos dijo es quién inventó la trampa y quién metió a la economía en la trampa. No significa esto, en virtud de la "ley del péndulo", volver a lo contrario; porque incluso, de acuerdo a esa ley, por donde más veces pasa el péndulo es por el medio.

Sin duda, hay que volver a algo del pasado, a consolidar la estructura productiva interna, de acuerdo al orden natural económico, con la ayuda de planes de desarrollo económico y social y de una verdadera secretaría de asistencia técnica, porque los condecorados equilibrios macroeconómicos son efímeros, si la estructura intema es quebradiza. Además, los artífices actuales de la economía nacional no han inventado nada nuevo; descuidando la consolidación de la estructura productiva interna e imbuidos de los principios del Consenso de Washington, han conducido la economía a un proceso de largo estancamiento y creciente malestar social. No hay signos de autocrítica, en un momento en que es más urgente la necesidad del cambio.

\subsection{Cambiemos de rumbo}

Desde nuestro espejo retrovisor observamos que la década de 1990 hereda graves problemas económicos y sociales, agravados aún más por doce años de guerra y que, a su vez, fueron la causa radical del conflicto civil. Por una parte, la conflictiva desintegración del tejido social, efecto de la tradicional desigualdad de la riqueza y de los ingresos, del prolongado descuido de las políticas sociales, a favor de los sectores más desprotegidos, de la rotunda oposición a las reformas elementales (tributaria, agraria...) y del irrespeto a la voluntad ciudadana, en los repetidos fraudes electorales, tal como lo afirmó la "proclama" de los militares jóvenes, que dieron el golpe de Estado, en octubre de 1979. Las convulsiones sociales de los setenta y la brutal represión militar, incluida una auténtica persecución religiosa, vinieron a desgarrar aún más la convivencia social y política.

Por otra parte, el debilitamiento del tejido económico, es decir, de la estructura productiva nacional, que la guerra prolongada profundizó aún más. El único modelo que imperó, en la década de los ochenta, fue la "economía de guerra" y la "gue- rra a la economía" por ambos flancos, que dieron al traste con las reformas estatistas, implantadas al inicio de la guerra, sin que esto sirva de disculpa a los errores de la administración pública. Lo opuesto a una economía de guerra sería una "economía de reconstrucción", como en Europa occidental, después de 1945, y no una "economía de mercado", al estilo del Consenso de Washington, para la cual no había una predisposición social y, menos aún, una consistencia económica productiva.

Tenemos que admitir que la década de 1990, es decir, sus gobiernos, heredaron este doble desgaramiento del tejido social y económico. Al mismo tiempo, afirmamos que las medidas económicas y sociales, derivadas del "pensamiento único" ("el modelo no se discute"), no han corregido, sino que han agravado la ruptura del tejido económico y social. En el corto plazo, tenemos que admitir como un "dato" el crecimiento acelerado de la población, que podrá autoplanificarse, a través de una mayor inversión en educación y desarrollo humano. Pero, al mismo tiempo, es motivo de seria reflexión que miles y miles de salvadoreños se lancen a una arriesgada aventura para poder gozar de unos ingresos familiares, que les son negados en su país. El monumento al "Hermano lejano" nos recuerda que nuestro modelo económico no puede atender a todos los "hermanos cercanos" y que necesita de hermanos lejanos para poder sobrevivir. Digamos, por lo menos, que esto plantea un serio desafío económico y social.

Ahora el desafío número uno es la recomposición del tejido social para poner fin al malestar general, al entorno de agresividad e inseguridad, a la apatía y desconfianza en las instituciones públicas, a la desesperanza y a la huida del país. A su vez, la recomposición del modelo económico, así como la reconstrucción de la estructura productiva deben orientarse a dar respuestas progresivas al problema número uno, la integración del tejido social. Esto significa que el éxito del modelo económico no debe reducirse a los incrementos del PIB, condición necesaria, pero no suficiente, sino que debe medirse por el desarrollo de "la plena libertad social". El modelo ha fracasado, en el logro de ambos objetivos.

Las estadísticas oficiales del Banco Central de Reserva, los informes de desarrollo humano y los análisis de coyuntura económica de distintas instituciones, muestran que la economía ha entrado en un serio desequilibrio estructural. En el análisis de coyuntura económica del Departamento de Econo- 
mía del primer semestre de 2002, se dice: "El análisis de la evolución de corto plazo, nos lleva a concluir que el año 2002 será el séptimo año consecutivo de práctico estancamiento económico. Consecuentemente, afirmamos que el modelo económico y social vigente es insostenible e inviable para encarrilar a El Salvador, en el tren del desarrollo económico y social, y el mismo requiere de nuevas medidas de política económica y social, que alteren sus estructuras. Ello es un llamado de urgencia a la creatividad y al protagonismo de los que tienen en sus manos las riendas del país; mayor apertura al diálogo y una mayor participación de los diversos sectores en las propuestas de solución".

Aquí se indica un defecto congénito de los últimos gobiernos. Se negaron a dar voz al pactado Foro de Concertación Económica y Social, después de 1992. Archivaron los programas económicos y los planes de nación, presentados por institutos de investigación y grupos de profesionales, en 1997-1999. En el año 2000 se impuso la dolarización, en forma inconsulta y festinada, y algunos ministros o presidentes del banco central han dado repetidas muestras de prepotencia y oídos sordos a otras opiniones autorizadas. El discurso del presidente Flores del 1 de junio de 2003, en el cuarto año de su mandato, es un triste ejemplo del autoengaño y del ocultamiento de los problemas estructurales, económicos y sociales, tras una catarata estadística, que más bien es espejismo que realidad.

El informe del Departamento de Economía continuaba diciendo: "El llamado no es caprichoso, pues desde hace varios años, diversos análisis de coyuntura económica (1998-2002) nos vienen señalando los mismos problemas: lento crecimiento económico, demanda agregada deprimida con bajos niveles de ahorro e inversión privada; alto desempleo y subempleo, pérdida del poder adquisitivo de los salarios mínimos y estancamiento del salario promedio; elevado déficit fiscal, creciente déficit de la balanza comercial, poco dinamismo de las exportaciones; deterioro de la mora bancaria y reducción del crédito al sector privado y poca inversión extranjera. A los síntomas presentados en este informe se añaden otros mencionados en diversos estudios, como el fuerte deterioro ambiental, la baja competitividad del aparato productivo, insuficiente inversión en educación - a pesar del esfuerzo realizado en esta área-, los altos niveles de delincuencia, inseguridad jurídica e insuficiencia de mano de obra calificada". Los cuadros y comentarios pueden consultarse en la revista $E C A$ (2002, pp. 730-770). El análisis de coyuntura del segundo semestre de 2002 muestra que la economía sigue estancada, pese a la dolarización ( $E C A$, 2003, pp. 43-72). A todo ello se sumaba el fenómeno de la concentración de la riqueza, comentado por J. Stiglitz, en el nivel mundial, tal como aparece en la tesis "el bloque empresarial hegemónico salvadoreño" (ECA, 2002, pp. 605-694).

Trece años de gobierno bajo la égida del Consenso de Washington y siete años consecutivos de estancamiento económico y desigualdad social es tiempo suficiente para reconocer que en El Salvador se vive "el malestar de la globalización". Es muy mala disculpa decir que nuestra economía anda cabizbaja, porque la economía mundial ha entrado en un proceso de recesión. Es cierto que dependemos de la marcha de esas economías, pero también es cierto que ellos dependen muy directamente de la globalización neoliberal, que han impuesto al mundo. A ellos les toca evaluar su globalización, como dijimos antes, por los efectos negativos que ha generado y que aparecen en la serie de sus cumbres mundiales. A nosotros nos toca evaluar cuáles han sido sus efectos, en nuestra economía, es decir, los efectos de nuestra sumisión.

El informe decía: "Más recientemente, economistas de reconocido prestigio académico, como Joseph Stiglitz y Jeffrey Sachs, han planteado duras críticas al proceso de globalización, a la generalización de recetas para lograr el desarrollo, y sus recomendaciones por parte del Fondo Monetario Internacional y Banco Mundial, con el aval de los gobiernos de turno". Esa globalización ha sido calificada de "hipócrita", porque promete, a sabiendas, lo que no puede lograr: promete la unificación y logra la mayor división de la humanidad. A nosotros nos toca evaluar los parámetros del Consenso de Washington, impuestos para integramos en la falsa globalización. Para todos ha llegado la hora de decir la verdad.

"Cambiemos de rumbo" requiere nuevos principios doctrinarios. Un primer paso necesario es la búsqueda de nuevos consensos en relación con el modelo económico y el tipo de país que se quiere construir. Comencemos por cosas sencillas que ya tenemos y que nos aportan nuevos parámetros del modelo económico y del tipo de país. Disponemos, desde 1999, de análisis del estado de la nación en desarrollo humano y de otros informes similares. No se trata de ninguna manera de arrinco- 
nar los documentos de la contabilidad nacional, reproducidos en la revista trimestral del Banco Central de Reserva, ni otros documentos oficiales, que sirven de base a los análisis de coyuntura económica.

El nuevo modelo económico debe inspirarse en lo que el Premio Nobel de Economía, Amartya Sen, llama "la libertad individual, en el sentido más amplio, como una condición de vida compartida" que, para ello, debe evaluarse, desde los parámetros de desarrollo humano, cuyo concepto se ha ido enriqueciendo. En los índices de estos informes se intercalan ítems sociales similares: ampliación y profundización de la democracia, participación de la gente, seguridad humana, equidad y desarrollo social, en sus componentes de educación, salud, vivienda, mercado laboral, crecimiento y estabilidad económica, la democracia en transición y los diversos derechos humanos, descentralización y desarrollo local, y el problema del agua como caso especial. El informe sobre desarrollo humano de 1999 analizaba estos mismos temas, de cara a la mundialización. Estos análisis descienden, en forma académica, a detalles y situaciones bien concretas y sugieren medidas y nuevas propuestas.

Estos informes son importantes por varias razones. Primero, completan el parámetro del crecimiento con el paradigma del desarrollo humano. Estos informes han sido preparados por diversos institutos de investigación, organizaciones no gubernamentales e instituciones dedicadas al desarrollo social. Es una forma de sacar del olvido a los programas económicos, antes presentados, como las Bases para un plan de nación, Temas claves para un plan de nación: consulta especializada, Crecimiento estéril o desarrollo, Crecimiento con participación... Se integraría así una mayor participación de la sociedad. En tercer lugar, motivaría a las facultades de ingeniería a sacar a la luz el mosaico de tecnología aplicada, que han ido acumulando en sus diversas disciplinas y que serían el Consejo Nacional de Ciencia y Tecnología ampliado a la nación. Lo que tenemos que fortalecer, como punto de partida, es el "consenso de El Salvador".

\subsection{Primero: construir el tejido social}

Los análisis económicos y los informes de desarrollo humano muestran que el tejido social se ha ido desgarrando, al ser una pequeña minoría quienes toman las decisiones políticas que afectan a todos. El error clave de nuestros tres gobiernos ha sido que, criticando el centralismo de los llamados socialismos reales, repiten una historia similar como "gobiemos de minorías", porque el Consenso de Washington es un "modelo para minorías". Los grupos de poder están representados en asociaciones reconocidas - la Asociación $\mathrm{Na}$ cional del la Empresa Privada, la Asociación Nacional de la Banca Salvadoreña y otras-, las cuales son consultadas por ser la voz de los que tienen voz. Al mismo tiempo han perdido poder y resonancia los movimientos sindicales y la representación laboral, a lo cual ha colaborado el proceso de privatización. Crece cuantitativamente el sector informal de la pequeña y microempresa, cuyos miembros no logran ser sujetos del crédito bancario y tampoco gozan de una protección legal, frente a quienes los subcontratan. Si desde la cumbre de Beijing, de 1996, se habla de economía y género es porque el sector femenino ha sido, en su sentido etimológico, "menos-preciado", en los contratos laborales, la maquila es un ejemplo. El sector campesino se halla indefenso, pues no está representado e incluso se recela del régimen de cooperativas. La seguridad social es privilegio de relativas minorías y la hamaca hundida de nuestra curva de Lorenz o el elevado coeficiente de Gini son el resultado de la desintegración social.

Con mucha razón los sociólogos dicen que no puede haber un crecimiento económico duradero con serios desequilibrios sociales. "La economía de mercado crea desequilibrios y fuerzas de acumulación y de exclusión que amenazan los equilibrios básicos de la sociedad. Para restablecer estos equilibrios se requiere la intervención del Estado y de otros agentes políticos y sociales" (Alain Touraine). Está comprobado que el progreso social no nace como una consecuencia del crecimiento económico. La tesis más confirmada por la historia es que el progreso social es un requisito del crecimiento económico duradero. Se trata de un crecimiento compartido, de acuerdo al principio de solidaridad. En esta misma línea, Amartya Sen considera "La libertad individual como un compromiso social. El contenido de la libertad individual incluye, de un lado, aquellos medios e instrumentos positivos que nos hacen posible actuar como individuos viables y responsables, incluyendo cuidados básicos de la salud, educación básica, estar libre del hambre y de la pobreza extrema, etc. También incluye, por otra parte, nuestras libertades y derechos básicos, la libertad y la oportunidad de participar en los procesos políticos y sociales, que afec- 
tan a nuestras vidas. La libertad se valora en este marco tanto en su sentido positivo, cuanto en su aspecto negativo... El compromiso social central tiene que incluir los derechos elementales de participación, que haga posible que los ciudadanos interactúen y decidan sobre valores y prioridades" (Vivir como iguales, Barcelona, 2000, p. 35). Dejemos de medir el bienestar nacional por el crecimiento del PIB y utilicemos el parámetro de la libertad social. De esta forma se nos plantea una nueva altemativa.

Esta nueva altemativa exige poner fin a la dicotomía mercado versus Estado y viceversa; una discusión estéril que enfrenta dos instituciones que se requieren mutuamente $y$ se complementan para el buen funcionamiento de la economía. Ambas instituciones presentan problemas, debilidades y potencialidades. "El mercado nunca se hará cargo de la equidad, en la sociedad, ni tampoco es eficiente por sí solo (competencia imperfecta, externalidades, información asimétrica, bienes públicos, etc.); por su parte, el Estado tampoco es garantía de eficiencia, honradez y transparencia, pero se le necesita para regular el mercado, para promover la equidad, la eficiencia y el desarrollo. Es urgente defïnir con seriedad el rol que cada uno puede y debe jugar en la sociedad, sin satanizar ni canonizar. Esto decíamos en los análisis de coyuntura del año 2002.

\subsection{Planes de desarrollo económico y social}

El movimiento mundial, que pide ensamblar lo económico en lo social, nos aconseja regresar a la elaboración "concertada" de planes de desarrollo económico y social. Se trata de acercar Estado y sociedad. En la filosofía de la economía de mercado se habla de un Estado mínimo, con una función subsidiaria. En realidad, los tres últimos gobiernos han hecho o han sido todo lo contrario. Han hecho un "Estado máximo", un gran maestro que no escucha a nadie, que se siente dueño del saber y de la verdad, que archiva las propuestas de la sociedad y, en consecuencia, ha fracasado en su función subsidiaria. Esto requiere, ciertamente, un cambio de gobiemo, o un cambio de mentalidad, en el próximo gobierno. "La nación debe ser consultada" para el buen ejercicio de gobierno, y la nación se está expresando con planes o programas de nación, con análisis de coyuntura económica e informes de desarrollo humano.

¿Por qué volver a hablar de planes de desarrollo económico y social? Porque aquellos planes de 1968-1972 y 1973-1977 comenzaban diciendo la verdad sobre la infraestructura social y económica, en su dimensión geográfica, y generaban una "conciencia" nacional de esos problemas y también de la necesidad urgente de programar soluciones. En la década de los noventa, se perdió la "tradición (entrega) de la verdad" y la verdad sigue siendo la gran "víctima". Se necesitan personas que, desde arriba y desde abajo, nos digan la verdad, que se traduce en conciencia y en espíritu de colaboración.

En aras de la "verdad", y a modo de ejemplo, vale la pena introducir un breve paréntesis para recordar que ya hemos dejado "realmente" de crecer. Al comentar la cumbre de Johannesburgo ("La tierra se recalienta") recordamos el estudio de FUSADES, El desafío salvadoreño: de la paz al desarrollo sostenible, de mayo de 1997. En este estudio se demuestra, con cifras conservadoras, que el "costo de la degradación ambiental equivale al 5 por ciento del PIB, que era igual a la tasa promedio de crecimiento de los años 1992-1995. Después de 1997, al mismo tiempo que se mantiene el costo de la degradación ambiental, las tasas de crecimiento oscilan entre el 3.5 y el 2 por ciento. Por lo tanto, no estamos tan errados cuando decimos que 'realmente' estamos en fase de un prolongado decrecimiento" (ECA, 2002, pp. 774-776). Se trata simplemente de recordar que éste es uno de los problemas al cual el próximo gobiemo debe prestar atención porque, antes y después de los terremotos de 2001, sectores poderosos del país no lo han hecho.

Cuando se habla de planes de desarrollo económico y social surge, con buena razón, el miedo a crear más burocracias, un nuevo ministerio. No 
es ésta la propuesta, porque se trata más bien de acercar e integrar las instituciones públicas existentes. Sin duda, habrá otras alternativas. El Estado es responsable de orientar la economía y regular el mercado. Economía y mercado no son nociones abstractas, sino una realidad concreta, cuya estructura productiva se presenta - entre otros radares- en las matrices intersectoriales, que el banco central elaboró para los años 1978 y 1990 . Al parecer, la matriz de 2000 está siendo actualizada. Por desgracia, en la década de 1990, las matrices quedaron embodegadas y las políticas económicas zigzageaban, sin una referencia a la economía intema, entre la maquila, la privatización y la dolarización.

Se ha pretendido dirigir la economía con unos programas monetarios y financieros, hechura del Fondo Monetario Internacional, al servicio del control de la inflación. Pero unos programas monetarios, desconectados de la estructura productiva nacional, no podían orientar el flujo de créditos hacia un crecimiento armónico de sectores con mayor capacidad para dinamizar la economía interna. La Asociación Nacional de la Empresa Privada y FUSADES ya advirtieron, en 1994. Con el advenimiento de la turbodolarización muchas personas lamentan la pérdida de la política monetaria. Tristemente, no es mucho lo que perdimos, la desconexión de dicha política de la estructura productiva nacional, llevó a un prolongado estancamiento, que el comercio internacional, por sí solo, no puede remendar. Por ello, los aclamados equilibrios macroeconómicos son algo ficticios, pues la estructura productiva intema sigue cada vez más desvertebrada, como lo demostrará la anunciada matriz del año 2000. Si no fuera por los 2 mil millones de pobre-dólares, ¿dónde estaría nuestra economía?

Necesariamente, debemos regresar a los planes de desarrollo económico y social, presentando algunas sugerencias. Es una buena noticia saber que el Banco Central de Reserva está actualizando la matriz insumo-producto de 2000 , porque ello permitiría hacer análisis comparativos con la matriz de 1990. El banco central cuenta con un excelente grupo de técnicos, con experiencia en los distintos departamentos de la institución. Sería una gran pérdida que el Banco Central de Reserva se disolviera, porque ya no emite colones o para que no emita colones. Si entre otras funciones tradicionales, los técnicos de la institución actualizaran estas matrices, el banco podría ser el asesor calificado de los ministerios de Economía, Agricultura, Medio
Ambiente y Hacienda, ya sea que lo haga directamente, ya sea que la asesoría se canalice a través de una secretaría de asistencia técnica de Casa Presidencial. No se trata de crear más ministerios, sino de integrar los ya existentes, siempre y cuando se ponga fin al top secret. Con colones o sin colones, el Banco Central de Reserva podría asesorar la canalización del crédito hacia los sectores que más se necesita revitalizar. ¿Querrá el sistema bancario canalizar su crédito hacia aquellas ramas productivas que muestren mayor capacidad para dinamizar el conjunto de la economía?

Estos planes de desarrollo tendrán mayor eficacia económica y social si los programas económicos, los análisis de coyuntura económica, los informes de desarrollo humano y otros análisis y propuestas técnicas emanen de las facultades de ingeniería llegasen hasta las instituciones de gobiemo, dado el retraso técnico que aún existe. Lo que buscan estas sencillas sugerencias, tal vez utopías, es mostrar la necesidad de reestructurar nuestra economía interna. Después de 1992 se inició la reconstrucción de la economía por el techo: la mayor parte del crédito se desbordó hacia el comercio, basado en importaciones, que no movilizan la economía intema, sin que quedara ahorro, ni políticas encaminadas a alentar la inversión de mediano plazo, en la manufactura y agricultura, generadoras de mayor empleo, ingresos y divisas. Ahora sufrimos las consecuencias.

En la década de los noventa, sea por convicción propia de los gobernantes o por imposición de las instituciones antes mencionadas, hemos quebrado el orden natural de la economía y hemos descuidado el potencial dinamizador del mercado interno, para asentarnos en una mayor terciarización económica y en una excesiva "propensión hacia el exterior". En la actualidad, la agricultura ha sido relegada al último plano y su vinculación intersectorial con el resto de la economía, como oferente y como demandante, es demasiado pobre; sin embargo, toda experiencia exitosa de desarrollo ha pasado, necesariamente, por el desarrollo de la agricultura. ¿Cuál debe ser el nuevo rol de la agricultura? ¿Qué tipo de agricultura se debe desarrollar? ¿Cómo se puede aprovechar para conservar el medio ambiente? ¿Cómo se pueden fortalecer los vínculos intersectoriales? Nos hacíamos estas preguntas en el análisis de coyuntura de 2002 , porque en el sector rural reside el sector más desprotegido, con menos esperanza de mejorar su empleo y sus salarios $y$, por 
añadidura, el más expuesto a la llegada de alimentos subvencionados, naturales o genéticamente modificados.

Sin entrar en el espinoso tema de la dolarización, sobre la cual la Asociación de la Banca Salvadoreña dijo: "sin lugar a dudas es dolarización" (La Prensa Gráfica, 24 de noviembre de 2000 , p. 12), encontramos que dos años después, pese a la reducción de las tasas pasivas y activas de interés, no hay efectos positivos sensibles, en nuestra economía, y no le echemos la culpa de todo a la economía internacional. "Pese a la dolarización, la economía no ha logrado salir del entrampamiento. Todos los sectores se encuentran deprimidos o estancados. Así lo demuestran los pocos estudios realizados en aquellos países que han adoptado la dolarización, cuyo mayor logro ha sido el control de la inflación. En la realidad, no existe ninguna evidencia para sostener que los países "dolarizados" han alcanzado tasas de crecimiento mayores que las de otros que no han implementado esta política monetaria. En tal sentido, se ha insistido en la necesidad de modificar las políticas económicas, así como también la de los ámbitos extraeconómicos, como la seguridad jurídica y ciudadana, que inciden también en la economía del país" ("Análisis de coyuntura económica. Segundo semestre del año 2002", $E C A, 2003$, pp. 43-72).

En todos los análisis de coyuntura económica, encontramos un creciente déficit de la balanza comercial, sostenida a flote por unas remesas, que tanto pueden crecer como decrecer, con un elevado déficit fiscal y una peligrosa deuda externa e interna, sin poder recurrir a una adecuada política monetaria y cambiaria. No debemos extrañamos, ni llamar mafiosos a grupos de personas o de académi$\cos$ que piden evaluar el proceso de la dolarización, sus efectos positivos y negativos, porque nos hemos quedado a la intemperie de las medias que tome Alan Greenspan. En cierto sentido, hemos tenido la suerte de que la dolarización haya coincidido con la fase descendente de la economía de Estados Unidos y sus tasas de interés son las menores posibles. Pero si esa economía se recupera y Alan Greenspan eleva sus tasas de interés, como en la década de los noventa, nos vamos a ver en una situación difícil y los capitales nacionales pueden abandonar el sistema bancario. Tampoco estamos en la capacidad de

reducir sensiblemente los impuestos para reactivar la economía, como lo ha hecho el gobierno de Washington. El problema resultante es que, en la práctica, la única palanca que nos queda para animar la economía es la política fiscal, que por cierto tiene el eje bastante quebradizo.

Ciertamente, la elaboración de planes de desarrollo con miras a lograr "la plena libertad social" y la consolidación económica, necesita una mayor intervención del Estado. De un Estado promotor del desarrollo, grande en eficiencia y capacidad, siempre que acepte la democracia participativa. Esto nos lleva a otro problema estructural: "la escasez de fondos públicos, insuficientes para atender las necesidades urgentes que tenemos". El Salvador se destaca por tener una de las "cargas tributaria" más bajas del hemisferio, alrededor del 11 por ciento del PIB. De Estado mínimo lo hemos convertido en Estado insuficiente e ineficiente para la promoción del desarrollo. La evasión de impuestos se ha convertido en "cultura" y la estructura fiscal es netamente regresiva. Esto es fruto de una política expresa de los actuales gobiernos, tal como lo explicó el Dr. Magaña, "siguiendo consignas de sectores económicamente poderosos".

Hay realidades que no se pueden disimular. Los tres gobiemos de tumo han hecho más desigual la estructura regresiva tributaria. "Demasiados impuestos matan los impuestos", se dijo, en referencia a los impuestos directos, en el supuesto de que el ahorro financiaría la inversión tecnológica. Pero la misma Asociación Nacional de la Empresa Privada reconoce que estamos rezagados, en la aplica- 
ción de los conocimientos tecnológicos. Parece que ese ahorro ha discurrido más bien por la corriente de las privatizaciones o a consolidar algunos oligopolios, que no cotizan, en función de sus beneficios. Otros sienten que cuando el Estado se siente pobre, se acuerda de los pobres para suprimir exenciones fiscales sobre medicinas y alimentos básicos. Era de esperar que un país donde la riqueza y los ingresos están tan concentrados, tributarían relativamente más los que disponen de mayores ingresos; pero no ha sido esa la situación.

Esto genera malestar en la población e ingresos insuficientes, en un Estado que debería incrementar la inversión social y enfrentar la reconstrucción nacional. Los técnicos en políticas fiscales advierten sobre la seriedad del problema: "A partir de 1996, la ejecución financiera del sector público no financiero (SPNF) muestra un deterioro creciente: déficit fiscal progresivo, la disminución del ahoro comiente, el estancamiento de la inversión bruta y un fuerte crecimiento de la deuda. En la actualidad existen dos situaciones que presionan sobre la carga fiscal: el costo de la reforma del sistema de pensiones y la necesidad de aumentar la inversión pública para hacerle frente a la reconstrucción nacional, después de los terremotos del año 2001. Adicionalmente, se debe agregar el traspaso futuro de los pasivos del Banco Central de Reserva de El Salvador al Ministerio de Hacienda, establecido en la Ley de Integración Monetaria. Los desequilibrios fiscales recurrentes y crecientes, aunados a todos los factores de presiones fiscales, evidencian que el desempeño de las finanzas públicas del país se encuentra en una senda de insostenibilidad de los déficit fiscales y del nivel de deuda del SPNF, que amenazan la estabilidad macroeconómica del país; por lo tanto, es necesario adoptar medidas de política fiscal efectivas para incrementar los ingresos tributarios y reducir los gastos del sector público, sin sacrificar la necesidad de inversión".

Llegados a este punto se confirman las conclusiones y recomendaciones hechas en nuestros análisis de coyuntura económica: "Consecuentemente, afirmamos que el modelo económico y social vigente es insostenible e inviable para encarrilar a $\mathrm{El}$ Salvador en el tren del desarrollo económico y social, y el mismo requiere de nuevas medidas de política económica y social, que alteren sus estructuras. Ello es un llamado de urgencia a la creatividad y protagonismo de los que tienen en sus manos las riendas del país: mayor apertura al diálogo y una mayor participación de los diversos sectores, en las propuestas de soluciones". Sin duda irán emanando muchas recomendaciones más concretas y más de corto plazo, que las aquí propuestas. El presente comentario cree que las nuevas propuestas requieren una nueva inspiración, algo muy distinto a los principios ideológicos que han informado la década de 1990. A este fin apunta el siguiente paréntesis.

\subsection{Un paréntesis: los programas económicos y sociales de Porto Allegre}

Recordamos que desde el año 2001, el nuevo milenio, el foro social de Porto Alegre se congrega en las mismas fechas en que lo hace el foro económico mundial de Davos. El foro social busca dos grandes objetivos: presentar la globalización, desde la visión de los sectores más inmersos en la sociedad civil, y su participación activa, en la formulación de un nuevo orden mundial. Aquí tenemos una primera fuente de inspiración. Nuestros gobiemos no han explicado a la sociedad civil cómo funciona la globalización, cuáles son sus ejes y actores, sus logros y sus fracasos. La práctica ha sido que el modelo se impone, no se discute, y la sociedad civil siente que no tiene participación activa en la formulación de un nuevo orden económico.

No es que en el foro social mundial, hoy en Porto Alegre, y, en el 2004, en India, vayamos a encontrar recetas económicas concretas, a nuestra medida, pero sí una inspiración, un punto de partida: analicemos la economía mundial y desde ahí reflexionemos sobre nuestros problemas nacionales. En la presente globalización cohabitan dos mundos distintos y lo que ahora se busca es una "globalización global", donde quepa toda la humanidad. Los cuatro ejes mayores del programa de Porto Alegre parecieran propuestas de extratertestres, pero pueden inspirar: a) la producción de riqueza y la reproducción social, comercio mundial, corporaciones multinacionales, control de capitales financieros, deuda extema, trabajo y economía solidaria; b) el acceso a las riquezas y la sustentabilidad, saber, derechos de reproducción y patentes, medicamentos, salud, ayudas, sustentabilidad ambiental, el agua, un bien común, pueblos indígenas, ciudades, poblaciones urbanas y soberanía alimentaria; c) la afirmación de la sociedad civil y los espacios públicos, combatir la discriminación y la intolerancia, democratización de las comunicaciones y de los media, producción cultural, diversidad e identidad, 
perspectivas del movimiento global de la sociedad civil, cultura de la violencia: violencia doméstica, migraciones, tráfico de personas (mujeres, niños y refugiados) y educación; d) poder político y ética en la nueva sociedad, organismos internacionales y arquitectura del poder, democracia participativa, soberanía, nación, Estado, globalización y militarismo, principios y valores, derechos humanos: derechos económicos, sociales y culturales (Entorno económico mundial, pp. 222-223).

Encontramos aquí dos escenarios, cuyos telones y bambalinas se mueven y se interponen. La mayoría de organizaciones no gubernamentales y muchos delegados estuvieron presentes, como manifestantes pacíficos, en las cumbres mundiales de Seattle, Génova, Praga, Québec, etc. y junto con el resto de académicos, conocen muy bien qué es "la globalización desde arriba": comercio mundial, multinacionales, organismos internacionales, capitales financieros, derecho de propiedad intelectual... Conocen muy bien el reverso de la medalla: la deuda externa, el mercado del trabajo, la salud y los medicamentos, la sustentabilidad ambiental, el agua bien común, la soberanía alimentaria, la cultura de la violencia... Lo que buscan es refundir el anverso y reverso de la medalla, de manera que llegue a reinar la ética, en la nueva sociedad, gracias al movimiento global de la sociedad civil.
En Porto Alegre se busca construir una "globalización desde abajo". Si se quiere reconstruir el mundo hay que comenzar por reconstruir las sociedades: la afirmación de la sociedad y el movimiento global de la sociedad civil. Porto Alegre es una radiografía de la globalización, vista desde el tercer mundo, y una radiografía del tercer mundo, vista desde los perdedores de la globalización, porque, en expresión de F. Hinkelammert, "existe un tercer mundo al interior del primer mundo y un primer mundo dentro del tercer mundo". En Porto Alegre se congregan los inconformes del primer mundo y del tercer mundo. La propuesta es un programa moralizante: la ética, en la nueva sociedad. Los derechos humanos, económicos, sociales y culturales; principios y valores. La democracia participativa y una economía solidaria. En Porto Alegre se critica la globalización desde arriba, para que los "maestros del mundo" hagan algo para humanizarla, y al mismo tiempo, se invita a construir una globalización humana "desde abajo", que harta tarea supone. Lo que moviliza a estos miles y miles de congregados es crear una cultura de la esperanza: "otro mundo mejor es posible". Nuestros candidatos presidenciales y sus equipos asesores, ¿tendrán a bien inspirarse en estos principios doctrinarios de Porto Alegre? ¿Estaremos equivocados al hacer esta sugerencia? 